\title{
PERCEPÇÃO DE SUCESSO NA CARREIRA: UM ESTUDO COM DOCENTES DE UNIVERSIDADES FEDERAIS DO RIO GRANDE DO SUL
}

\section{PERCEPTION OF SUCCESS IN THE CAREER: A STUDY WITH THE TEACHERS OF FEDERAL UNIVERSITIES OF RIO GRANDE DO SUL STATE}

\author{
Martiele Gonçalves Moreira \\ Mestranda em Administração - UNIPAMPA- Campus Santana do Livramento \\ Santana do Livramento, RS, Brasil \\ E-mail: martiele18moreira@gmail.com \\ Andressa Hennig Silva \\ Professora Assistente na UNIPAMPA- Campus Santana do Livramento, \\ Santana do Livramento, RS, Brasil \\ E-mail: andressasilva@unipampa.edu.br \\ Michel Everton Ramos Gomes \\ Graduado em Administração na UNIPAMPA- Campus Santana do Livramento, \\ Santana do Livramento, RS, Brasil \\ E-mail: michel.ramos.gomes@gmail.com
}

\section{RESUMO}

$\mathrm{Na}$ intenção de galgar sucesso profissional, muitos indivíduos acabam optando por priorizar a esfera do trabalho, preterindo assim a esfera familiar, o que vai contra o propósito do autogerenciamento da carreira, principalmente no caso das mulheres, uma vez que, na maioria das vezes além da carreira profissional, ainda são responsáveis pelas atividades da casa e com os filhos. Neste cenário, o objetivo desse estudo visa identificar a percepção de sucesso na carreira das docentes do gênero feminino das Universidades Federais do Rio Grande do Sul. O estudo teve abordagem quantitativa, método survey contanto com 298 respondentes, os dados foram analisados por meio de estatística descritiva e teste T de Student. Dentre os principais resultados cita-se que as docentes percebem mais seu sucesso através da dimensão subjetiva, também foi possível perceber que as docentes que ocupam cargo de gestão percebem mais o sucesso na carreira, em relação as que não ocupam.

Palavras-chave: Docentes. Percepção de Sucesso. Carreira. Survey. Mulheres.

\begin{abstract}
In order to achieve professional success, many individuals choose to prioritize the sphere of work, thus neglecting the family sphere, which goes against the purpose of self-management of the career, especially in the case of women, since, in most cases beyond careers are still responsible for the activities of the home and children. In this scenario, the objective of this study is to identify the perception of success in the career of the female teachers of the Federal Universities of Rio Grande do Sul. The study had a quantitative approach, counting with 298 interviewees, the data were analyzed through descriptive statistics and Student's $T$ test. Among the main results it is mentioned that the teachers perceive more their success through the subjective dimension, it was also possible to perceive that the professors who occupy the position of management perceive more the success in the career, in relation to those that do not occupy.
\end{abstract}

Keywords: Teachers. Perception of Success. Career. Survey. Women.

Data de submissão: 13 de dezembro de 2016.

Data de aprovação: 16 de março de 2017.




\section{INTRODUÇÃO}

Vive-se atualmente na Era do Conhecimento, como é chamado o século XXI, e juntamente com essa valorização do conhecimento sobressalta um ambiente de trabalho instável e competitivo, no qual, se torna tão importante a interpretação pessoal do indivíduo sobre sua carreira, quanto às possibilidades de crescimento objetivo na organização e na vida pessoal (ARTHUR et al., 2005). Assim, o indivíduo está gerenciando a sua trajetória profissional para conseguir delimitar e ter maior controle sobre as fronteiras do trabalho e da família (STURGES, 2008), priorizando a conduta de forma subjetiva na carreira, e quando estes não percebem o seu sucesso, facilmente podem vir a mudar de organização (COSTA, 2010).

Dessa forma, o indivíduo compromete-se mais consigo mesmo buscando o sucesso de formas alternativas, de modo que a organização necessita utilizar de outras formas além da remuneração para reter o seu funcionário, "e muitos, sobretudo mulheres, têm saído da carreira corporativa buscando maior balanço vida-trabalho ou outras atividades que Ihes deem maior realização" (COSTA, 2010, p.13). Este novo cenário transforma as relações de trabalho, concedendo maior poder de barganha entre funcionários e chefes, a fim de estabelecer um ambiente de trabalho satisfatório para ambas as partes, assim, alcançando uma maior percepção de sucesso profissional.

Entretanto, para alcançar o sucesso profissional, muitos indivíduos priorizam a esfera do trabalho, deixando a esfera familiar em segundo plano, o que vai contra o propósito do autogerenciamento da carreira. Logo, a jornada de trabalho, ocupa a maior parte do tempo do trabalhador, e o mesmo não se permite desfrutar do seu tempo livre, pois prefere dedicar-se ao trabalho na busca incessante pelo sucesso, dificultando assim, a vida social.

Para os professores de ensino superior, que obedecem à lei do regime de dedicação exclusiva nas Instituições Federais de Ensino Superior (IFES), cumprindo quarenta horas semanais, se torna ainda mais fatigante a missão de conciliar casa e trabalho. Devido às inúmeras atividades que o docente exerce juntamente com a constante atualização do conhecimento, com o intuito de progredir nas classes da carreira, que vão desde professor auxiliar, assistente, adjunto, associado até professor titular, o professor universitário acaba invadindo as horas de lazer para dar conta de tantos encargos.

Homens e mulheres exercem na docência as mesmas funções, porém, as mulheres totalizam um maior tempo de trabalho por serem responsáveis, na maioria dos casos, pelos trabalhos domésticos (ALVARENGA, 2008). Assim, sua percepção de sucesso na carreira pode envolver outras variáveis, além de somente a sua trajetória profissional. Dessa forma, tem-se o problema de pesquisa: Qual a percepção de sucesso na carreira das docentes do gênero feminino das Universidades Federais do Rio Grande do Sul? No qual, busca-se identificar a percepção de sucesso na carreira das docentes do gênero feminino das Universidades Federais do Rio Grande do Sul. E, especificamente pretende-se: i) Descrever o perfil sócio-demográfico das respondentes; ii) Verificar a diferença na percepção de sucesso na carreira das docentes que são mães; iii) Averiguar se existe diferença na percepção de sucesso da carreira nas docentes que ocupam cargo de gestão; e por último, iv) Investigar se existe diferença na percepção de sucesso da carreira nas docentes em relação a titulação acadêmica que possuem. 
Com a realização deste estudo, pretende-se auxiliar na compreensão do que move um docente, o que o estimula para permanecer na docência e como este está tratando da sua carreira em busca do seu sucesso profissional. Pois, os professores do ensino superior não possuem uma identidade singular, apresentam diversas características, principalmente em relação às Instituições de Ensino que trabalham, e são ainda mais diferenciados no que tange a sua formação profissional e sua trajetória de vida (PEREIRA; ANJOS, 2014). Fatos que são sentidos unicamente pelo docente, e quando falamos em docentes do gênero feminino, a sobrecarga inerente da profissão juntamente das expectativas geradas pela sociedade sobre as mulheres que são estereotipadas e vistas como mulheres do lar (O'NEIL, 2003) são fatores que podem vir a diferenciar a percepção de sucesso entre os gêneros.

Para tanto, o artigo foi organizado em cinco partes. A primeira parte é esta introdução, seguido de um levantamento bibliográfico pertinente ao estudo. A terceira parte contempla o caminho metodológico que foi adotado para a realização do estudo, seguido da quarta parte onde se apresentou a análise e discussão dos resultados, e por fim, a quinta parte apresenta as considerações finais do estudo.

\section{REFERENCIAL TEÓRICO}

No presente capítulo, apresenta-se o embasamento teórico necessário para dar sustentação à pesquisa. O qual está subdividido em tópicos e subtópicos, que abordarão a mulher na docência, e os conceitos sobre a percepção de sucesso na carreira.

\section{A Ascensão das Mulheres e a Docência Universitária}

A primeira onda do movimento feminista que atuou fortemente, entre 1850 e 1930 foi um fenômeno político importante que concedeu vitórias significativas para as mulheres, como o direito a voto, acesso ao emprego, educação e direito ao divórcio. Essas conquistas contribuíram para que a mulher fosse considerada um ser público, diminuindo a exclusão que ocorria com as mesmas no âmbito social, e desde então, elas vêm angariando espaços e novas conquistas, de forma especial no mercado de trabalho.

Para O'Neil (2003) não se pode estudar a carreira da mulher sem compreender as influências que esta enfrenta. Há inúmeros fatores que podem intervir na ascensão da mulher em sua carreira, sendo que, a autora destaca três fatores: pessoal, organizacional e social. $O$ fator pessoal, diz respeito às influências que a mulher sofre no trabalho, referente aos desejos e escolhas que são inerentes a trajetória profissional. Estas escolhas e desejos afetam o relacionamento entre carreira e família, na decisão de ser mãe ou manter a estabilidade no emprego, e a opção por manter uma dupla jornada de vida.

As influências organizacionais são elementos implícitos ou explícitos que as organizações apresentam, geralmente enraizados na sua cultura. Esses fatores impedem que as mulheres cheguem a cargos de alta responsabilidade e poder, excluindo as mulheres de cargos gerenciais. E por último, as influências sociais referem-se às expectativas que a sociedade imprime na mulher, definindo estereótipos e papéis que estas devem, naturalmente, exercer. Das mulheres espera-se um "ser dócil, frágil, compreensiva e submissa" 
(BOTELHO; MORAES; CUNHA, 2008, p. 4), dessa forma, quando uma mulher se comporta de maneira mais agressiva e direta acaba sendo má vista, já que este tipo de comportamento não é esperado.

Segundo levantamento do Censo de Educação Superior feito pelo Ministério da Educação (MEC) em 2013, a maioria dos docentes das IES trabalham em tempo integral. Os resultados ainda registram um aumento significativo e sequenciado do número de doutores atuando nas instituições, porém, para ambos os sexos, predominam os mestres. Todavia, as mulheres ainda se encontram em minoria frente aos homens na docência, com um total de 201.599 vínculos masculinos e 165.683 vínculos femininos. Corroborando com os esses resultados, os autores Jilou e Cecílio (2015, p. 1) afirmam em seu estudo que "referente às relações de gênero, houve uma predominância masculina no trabalho docente em nível universitário, o que difere do considerado ser a profissão predominantemente feminina".

O plano da carreira dos docentes, instituído pelo Ministério da Educação estabelece a carreira do Magistério Superior Federal no qual dispõe de cinco classes na carreira, são elas: Professor Auxiliar, Professor Assistente, Professor Adjunto, Professor Associado e Professor Titular. A primeira classe a ser ocupada pelo docente em início de carreira é o de auxiliar, sendo necessária a obtenção do título de mestre. Na sequência vêm as outras classes, e para progredir de um nível para outro é preciso concluir etapas e ter um bom desempenho acadêmico e científico.

Docência é o trabalho dos professores, porém na prática, os professores ultrapassam a ideia de ministrar aulas, necessitando desempenhar inúmeras funções. Estas funções se tornam muito complexas com o passar do tempo e com o surgimento de novas práticas de trabalho (VEIGA, 2005). E são essas funções agregadas, que o docente desenvolve, que os sobrecarregam, principalmente no caso das mulheres, em função das demais atividades agregadas ao seu cotidiano. "Assim, como em uma colcha de retalhos, as mulheres que ascendem em suas profissões precisam saber equilibrar diferentes demandas, anseios e as expectativas que recaem sobre elas, muito mais do que ocorre com os homens que chegam ao poder" (BOTELHO; MORAES; CUNHA, 2008, p. 5). Esse equilíbrio pode influenciar a percepção de sucesso das docentes, dessa forma, a seguir aborda-se este tópico com maiores esclarecimentos sobre o tema.

\section{Percepção de Sucesso na Carreira}

Pode-se observar, desde a virada do século XIX para o XX, que há claramente dois modelos de carreira distintos: o tradicional e o moderno (CHANLAT, 1995). O modelo tradicional corresponde a carreira que é feita para o homem, pertencente a um grupo social dominante, juntamente a uma sociedade que não permitia a entrada da mulher no mercado de trabalho. Na medida em que este cenário declina e o capitalismo toma a frente com sistemas de produção mais flexíveis, as mulheres se inseriram no meio laboral.

Então, a partir dos anos 70 surge o modelo moderno de carreira, caracterizado pela entrada da mulher no mercado de trabalho junto às minorias, elevação do grau de instrução escolar, direitos reservados, etc. Contrário ao modelo tradicional, o modelo moderno é marcado pela instabilidade, descontinuidade e horizontalidade (CHANLAT, 1995). Abaixo se tem o Quadro 1 que apresenta um comparativo entre os dois modelos, tradicional e moderno. 
Quadro 1 - As diferenças entre os dois modelos.

\begin{tabular}{|c|c|}
\hline O modelo tradicional & O modelo moderno \\
\hline Um homem & Um homem e/ou uma mulher \\
\hline Pertence aos grupos socialmente dominantes & Pertence a grupos sociais variados \\
\hline Estabilidade & Instabilidade \\
\hline Progressão linear vertical & Progressão descontínua vertical e horizontal \\
\hline
\end{tabular}

Fonte: (CHANLAT, 1995).

Ainda conforme o autor, esta transição, causa comportamentos e reações aos indivíduos que até o momento eram desconhecidos, como optar por estudar e trabalhar, dar uma pausa na carreira para cuidar dos filhos e depois voltar ao mercado de trabalho, entre outras reações que nem mesmo eram imagináveis no modelo tradicional de carreira. Percebendo estas rupturas no modelo tradicional que geraram o fenômeno de diversificação de carreiras, Chanlat (1995), readequou os modelos criando quatro tipos de agrupamentos a partir dos dois modelos anteriores: (1) burocrático; (2) profissional; (3) empreendedor; e (4) sociopolítico; descritos a seguir:

1- Burocrático: a carreira do tipo burocrática se encontra exatamente no modelo da pirâmide organizacional. Cada nível refere-se a certas responsabilidades com um salário estipulado e com vantagens sociais bem definidas. Atualmente, percebe-se que esse tipo de carreira está desaparecendo.

2- Profissional: esta carreira baseia-se na concentração de certo saber, de uma especialização. Seu avanço ocorre no interior da profissão, à medida que o conhecimento aumenta. É exemplos de carreiras a de um médico, professor, advogado, engenheiro, que se caracterizam pela mobilidade.

3- Empreendedor: a carreira empreendedora se desenvolve praticamente, de forma individual, estando ligadas as atividades de uma empresa própria. É mais arriscada do que as carreiras anteriores, porém, quando bem-sucedida, as recompensas monetárias são maiores.

4- Sociopolítico: envolve habilidades sociais e de relação de poder que uma pessoa dispõe. O capital de relações é parte fundamental para o sucesso nessa carreira.

Além dos tipos de carreiras, Hall (2002), identificou através de seus estudos, 4 significados distintos atribuídos ao termo carreira:

1- Carreira com movimentação vertical, independente da profissão, área ou organização;

2- Carreira como profissão, tal como médico, advogado, professor;

3- Carreira sequenciada de empregos durante a vida, o significado de carreira parte do princípio de que todo e qualquer trabalhador tem carreira;

4- Carreira como diversas experiências vivenciadas durante a vida, não sendo somente experiências profissionais; 
Estes significados, são os resultados de diversas mudanças estruturais no mundo laboral, percebe-se que o primeiro significado, refere-se a uma carreira rígida, respeitando a hierarquia, posteriormente, tem-se o significado de carreira atrelado às clássicas profissões. Já os significados 3 e 4 , partem para um princípio liberal, considerando carreira como os empregos obtidos durante a vida e as experiências vivenciadas.

De modo geral, carreira segundo Costa (2010), pode ser uma sequência de posições ocupadas por uma pessoa em função, não só do trabalho, mas como de outras experiências vividas, das suas percepções individuais, atitudes e comportamentos organizacionais. Que irão resultar em bagagem pessoal e profissional que auxilie no desenvolvimento de tarefas mais complexas e que estão em constante mudança.

O desenvolvimento do trabalhador resulta, dentre outros quesitos, de seu esforço, de sua capacidade e de sua persistência na consolidação do seu trabalho. E no ambiente acadêmico, o docente passa por situações adversas, mas se fazem igualmente relevantes para a sociedade contemporânea, por disseminar conhecimentos impulsionando o desenvolvimento do país (ROWE; BASTOS; PINHO, 2011). Para promover o conhecimento, o docente investe fortemente em sua carreira, administrando seu tempo e suas tarefas para alcançar o sucesso e ser reconhecido.

Para Gonçalves (2009, p. 23), a carreira do profissional docente é:

Um percurso relacional e contextualmente vivenciado e construído, em que a pessoa-professor se vai diacronicamente desenvolvendo, segundo um conjunto de etapas ou fases com características próprias, em espaços e tempos diferenciados e com necessidades específicas de formação.

As pessoas têm pensado as suas carreiras em formatos diferentes, cada vez tendo menos a empresa como referência para suas decisões e utilizando-se das oportunidades oferecidas pelo mercado para seu posicionamento profissional e a construção de seu futuro (ANDRADE; BARBOSA, 2013). Costa (2010), em sua tese, pontua diferentes categorias de carreiras, nas quais são tipificadas através de diferentes trajetórias de carreiras vivenciadas pelos indivíduos, no qual, em cada fase podem existir aspectos de prioridades na carreira, distintas uma das outras. Se estiver havendo sucesso nessa etapa da carreira, o indivíduo estará satisfeito, no momento em que não há satisfação, o mesmo pode focar em outra prioridade, sempre na busca pelo que Ihe satisfaça. Assim, a seguir apresenta-se um tópico sobre sucesso na carreira, na tentativa de elucidar esta dimensão.

\section{Sucesso na Carreira}

Sucesso na carreira pode ser definido como o acúmulo de resultados favoráveis, psicológicos e profissionais advindos de relações com o trabalho. Considera-se sucesso como um conceito avaliativo, então julgamentos de sucesso na carreira dependem da visão de quem está avaliando. Quando a avaliação ocorre de terceiros, os critérios de avaliação são embasados basicamente por questões objetivas e mensuráveis, podendo ser chamado de "sucesso objetivo na carreira". Porém, o julgamento pode ocorrer pelo próprio 
indivíduo que está na busca pelo sucesso, essa dimensão chama-se "sucesso subjetivo na carreira", sendo mensurado pelos sentimentos de realização e satisfação com a própria carreira (JUDGE et al., 1995).

"A maioria dos pesquisadores tem avaliado o sucesso na carreira por componentes extrínsecos e intrínsecos" (COSTA; DUTRA, 2011, p. 5). Os componentes extrínsecos, se referem a avaliação objetiva, consiste em resultados tangíveis (salário, promoções). Já os componentes intrínsecos, avaliação subjetiva, consiste na autoavaliação que o indivíduo realiza sobre o seu próprio sucesso, que leva em consideração o emprego, a carreira e a satisfação pessoal.

Fica claro, então, que existem duas formas de avaliação do sucesso na carreira, primeiramente a objetiva e após têm-se o modelo subjetivo. Porém, estas duas dimensões não consideram que a carreira implica em aprendizagem e desenvolvimento profissional. Sendo assim, Dutra (2002), ao propor um modelo de gestão de pessoas composto por três dimensões - movimentação, desenvolvimento e valorização- incluiu a carreira na dimensão do "desenvolvimento", e o progresso na carreira é avaliado pela ampliação das suas ocupações e a maior complexidade dos seus resultados. Esta dimensão considera os movimentos horizontais dentro da carreira, não apenas os verticais, no qual o indivíduo se sentirá satisfeito em ter maiores obrigações e a incumbência de tarefas mais complexas para serem realizadas.

No âmbito de trabalho, existe uma dificuldade ao analisar a percepção individual de cada trabalhador, de forma que a percepção envolve aspectos sentimentais e outros fatores relacionados diretamente à organização. Dois funcionários podem exercer a mesma função, porém, cada um deles poderá ter percepções diferentes, afetando, assim, seu desempenho organizacional (COSTA, VIEIRA, 2014).

Costa, Chiuzi, Dutra (2013), ao estudarem a percepção de sucesso nos docentes, averiguaram que os salários não apresentam impactos significativos frente aos reconhecimentos das competências, dos resultados como equipe, identidade e orgulho da profissão e da contribuição que eles fazem à instituição e a sociedade. "Isto indica que o professor que se sente competente no que faz e que nutre sentimentos positivos em relação a isso, sente-se mais bem-sucedido que aquele que está satisfeito com sua remuneração e seu cargo" (COSTA; CHIUZI; DUTRA, 2013, p. 111).

Lima et al. (2014), verificaram através de um grupo de docentes universitários, que a avaliação subjetiva é mais importante na visão destes docentes do que a avaliação objetiva. Corroborando com os autores supracitados, Costa e Dutra (2011) que identificaram estas duas formas de avaliação, subjetiva, referindo-se a autoavaliação, e objetiva, referente a resultados quantitativos.

Por fim, percebe-se que a percepção de sucesso na carreira depende predominantemente da avaliação subjetiva e objetiva, sendo a primeira de mais valia para o indivíduo. Assim, encerra-se o referencial teórico abordado nesta pesquisa e passa-se para a descrição da metodologia adotada no estudo. 


\section{MÉTODO DE TRABALHO}

Este estudo tem um caráter descritivo de abordagem quantitativa, utilizando como método o levantamento do tipo Survey. O enfoque quantitativo estabelece com exatidão os padrões de comportamento utilizando-se da estatística, e a partir da coleta de dados e análise dos mesmos responde as questões de pesquisa e testa as hipóteses previamente formuladas (SAMPIERI et al.). O procedimento para a coleta dos dados foi uma survey eletrônica, que segundo Hair et al. (2005), possibilita coletar informações de uma grande amostra de indivíduos, se valendo de um questionário para levantar informações quantitativas de maneira rápida e conveniente.

A coleta dos dados foi realizada com docentes do gênero feminino das Universidades Federais do Rio Grande do Sul, devido a disponibilidade para a coleta. A população do presente estudo é composta aproximadamente, segundo levantamento feito pelos autores através da coleta dos emails das docentes nos sites institucionais das Universidades Federais do Rio Grande do Sul, por 1.165 mulheres docentes, distribuídos pelas diversas áreas de atuação. A amostra pretendida adotando $5 \%$ de erro amostral é de um total de 298 respondentes, ou seja, o nível de confiança indica a probabilidade de apenas $5 \%$ de erro da pesquisa, por se tratar de uma amostra não probabilística e de amostragem por conveniência, visto que, o questionário foi respondido por aquelas que estiverem dispostas. Foram realizados dois envios dos questionários com espaço de tempo de duas semanas. Ao final da coleta dos dados, foram obtidos 356 questionários respondidos e aptos a participar da pesquisa, resultando em um número superior ao estipulado pelo cálculo amostral.

Os dados foram coletados através de um questionário online que foi enviado, no período de março a abril de 2016, para as professoras através do email institucional. Assim, posteriormente a coleta dos dados, estes foram tabulados no Excel e analisados através do software SPSS 20.0. O questionário foi composto por um bloco com perguntas sobre as docentes, com intuito de traçar o perfil sócio demográfico das respondentes e um segundo bloco que pretendia identificar a percepção de sucesso através da escala de percepção de sucesso (EPSCR) construída e validada por Costa (2010), em sua tese de doutorado. Esta escala foi adotada, devido seu alto nível de confiabilidade e por adequar-se aos objetivos aqui propostos pelo estudo.

O questionário apresentou uma escala tipo likert de 5 pontos e em valores absolutos assume-se como um fator baixo, quando a média é inferior ou igual a 2,0, médio para valores entre 2,1 e 3,9 e alto quando a média é igual ou superior a 4,0. Este autor baseou-se em vários outros autores que trabalham com diversas dimensões do sucesso na carreira. Optou-se por utilizar a versão reduzida da escala, composta por 10 itens, despendendo menos tempo para responder o questionário. No Quadro 2, resumidamente demonstram-se as características desta escala. 
Quadro 2 - Definições das dimensões e precisão (Alpha de Cronbach) da EPSCR em sua forma reduzida, com 10 itens.

\begin{tabular}{|c|c|c|c|}
\hline Dimensão & Definição & Itens & $\begin{array}{c}\text { Alpha de } \\
\text { Cronbach }\end{array}$ \\
\hline Objetiva & $\begin{array}{c}\text { Envolve resultados que os outros conhecem e normalmente usam } \\
\text { para avaliar a carreira da pessoa, tais como remuneração e status } \\
\text { hierárquico. }\end{array}$ & $\begin{array}{l}1,2,4, \\
9 \text { e } 10\end{array}$ & 0,81 \\
\hline Subjetiva & $\begin{array}{c}\text { Envolve resultados que têm valor para a própria pessoa, } \\
\text { independentemente dos resultados que as outras pessoas } \\
\text { conhecem sobre sua carreira, tais como sentir-se competente, } \\
\text { gostar e ter orgulho do que faz, estar em constante } \\
\text { desenvolvimento, inovar e realizar atividades gratificantes. }\end{array}$ & $\begin{array}{c}3,5, \\
6,7, \text { e } 8\end{array}$ & 0,80 \\
\hline EPSCR & Avalia a percepção de sucesso na carreira de uma pessoa que \\
trabalha há pelo menos cinco anos. & $\begin{array}{c}\text { Todas } \\
\text { acima }\end{array}$ & 0,83 \\
\hline
\end{tabular}

Fonte: Costa (2010).

Para analisar os dados coletados, foi empregada uma análise descritiva, na qual foi possível descrever, resumir e apresentar os dados coletados (COLLIS; HUSSEY, 2005). Foi descrito também, as medidas de tendência central sendo elas, média, desvio-padrão e mediana. Após a realização da descrição dos dados, para avaliar o grau de confiabilidade do questionário utilizou-se do Alpha de Cronbach. E para alcançar os objetivos propostos utilizou-se o Teste t de Student, a fim de "avaliar se dois grupos diferem entre si de maneira significativa com relação a suas médias" (SAMPIERI et al., 2006, p. 454). Assim, se pode testar uma hipótese na qual se estabelece que as médias dos grupos independentes sejam iguais, e dessa forma, avaliar se as diferenças encontradas entre as amostras ocorreram de forma ocasional ou se houve verdadeiramente uma diferença (HAIR et al., 2005). Para tanto, adotou-se um nível de significância de 0,05, ou seja, a hipótese será aceita somente se o valor for $<0,05$.

Através destes métodos estatísticos pretendeu-se alcançar os objetivos propostos e responder ao problema de pesquisa. A seguir, passa-se para a apresentação e discussões dos resultados.

\section{APRESENTAÇÃO E DISCUSSÃO DOS RESULTADOS}

No presente capítulo, serão realizadas as análises pertinentes aos procedimentos adotados e relatados no método do estudo. Inicia-se com o perfil da amostra das respondentes, seguido da percepção de sucesso das docentes, envolvendo as variáveis filho, cargo de gestão e titulação acadêmica.

\section{Perfil da Amostra}

A amostra foi composta por 356 docentes mulheres do Estado do Rio Grande do Sul, que preencheram o questionário de forma online. Na Tabela 1, encontram-se os resultados obtidos no que diz respeito ao perfil das respondentes. 
Tabela 1- Perfil dos Entrevistados

continua

\begin{tabular}{|c|c|c|c|}
\hline Variáveis & Alternativas & Frequência & Percentual (\%) \\
\hline Respondentes & Mulheres & 356 & $100 \%$ \\
\hline \multirow{6}{*}{ Estado civil } & Solteira & 69 & 19,4 \\
\hline & União Estável & 74 & 20,8 \\
\hline & Casada & 164 & 46,1 \\
\hline & Separada & 15 & 4,2 \\
\hline & Divorciada & 31 & 8,7 \\
\hline & Viúva & 03 & 0,8 \\
\hline \multirow{2}{*}{ Filhos } & Sim & 215 & 60,4 \\
\hline & Não & 141 & 39,6 \\
\hline \multirow{4}{*}{ Idade } & Até 35 anos & 12 & 4,4 \\
\hline & Entre 36 e 41 anos & 86 & 31,5 \\
\hline & Entre 42 e 51 anos & 87 & 31,9 \\
\hline & Mais de 52 anos & 88 & 32,2 \\
\hline \multirow{3}{*}{ Titulação mais elevada } & Especialista & 02 & 0,6 \\
\hline & Mestre & 56 & 15,7 \\
\hline & Doutora & 298 & 83,7 \\
\hline \multirow{5}{*}{ Universidade em que atua } & Unipampa & 98 & 28,7 \\
\hline & UFPel & 43 & 12,6 \\
\hline & UFSM & 61 & 17,9 \\
\hline & FURG & 07 & 2,1 \\
\hline & UFRGS & 132 & 38,7 \\
\hline \multirow{4}{*}{ Tempo na IES } & Até 6 anos & 216 & 56,46 \\
\hline & Entre 7 e 12 anos & 62 & 17,41 \\
\hline & Entre 13 e 21 anos & 39 & 10,96 \\
\hline & Mais de 22 anos & 54 & 15,16 \\
\hline \multirow{7}{*}{ Classe na Carreira } & Temporária & 04 & 1,1 \\
\hline & Substituta & 11 & 3,1 \\
\hline & Auxiliar & 05 & 1,4 \\
\hline & Assistente & 41 & 11,5 \\
\hline & Adjunta & 187 & 52,5 \\
\hline & Associada & 87 & 24,4 \\
\hline & Outra & 21 & 5,9 \\
\hline \multirow{9}{*}{ Área em que atua } & Ciências Exatas e da Terra & 53 & 14,9 \\
\hline & Ciências Biológicas & 22 & 6,2 \\
\hline & Engenharias & 22 & 6,2 \\
\hline & Ciências da Saúde & 57 & 16,0 \\
\hline & Ciências Agrárias & 42 & 11,8 \\
\hline & Ciências Sociais Aplicadas & 72 & 20,2 \\
\hline & Ciências Humanas & 57 & 16,0 \\
\hline & Linguística & 29 & 8,1 \\
\hline & Outra & 02 & 0,6 \\
\hline
\end{tabular}


Tabela 2- Perfil dos Entrevistados continuação

\begin{tabular}{cccc} 
Variáveis & Alternativas & Frequência & Percentual (\%) \\
\hline \multirow{2}{*}{ Exerce cargo de gestão } & Sim & 157 & 44,1 \\
& Não & 199 & 55,9 \\
\hline \multirow{3}{*}{ Tempo na docência } & Até 6 anos & 22 & 8,1 \\
& De 7 a 12 anos & 76 & 28,1 \\
& De 13 a 21 anos & 84 & 31,1 \\
& Mais de 22 anos & 88 & 32,6 \\
\hline \multirow{2}{*}{ Renda } & Até $\mathrm{R} \$ 8.000,00$ & 107 & 31,10 \\
& Entre $\mathrm{R} \$$ 8.001,00 e $\mathrm{R} \$ 12.000,00$ & 167 & 48,56 \\
& Entre $\mathrm{R} \$ 12.001,00$ e $\mathrm{R} \$ 20.000,00$ & 62 & 18,02 \\
& Mais de $\mathrm{R} \$ 20.001,00$ & 08 & 2,32 \\
\hline
\end{tabular}

Fonte: elaborada pelos autores, com base nos dados da pesquisa.

Pode-se observar na Tabela 1 que as mulheres casadas totalizam a maior porcentagem chegando a quase metade das respondentes $(46,1 \%)$, em seguida tem-se as mulheres em união estável $(20,8 \%)$, essas duas condições são semelhantes na sua forma de convívio entre dois cidadãos, somente se diferem em termos jurídicos. A terceira maior porcentagem são as das docentes solteiras $(19,4 \%)$, seguido das divorciadas $(8,7 \%)$, separadas $(4,2 \%)$ e viúvas $(0,8 \%)$. Destas, 215 mulheres $(60,4 \%)$ tem um ou mais filhos e 141 mulheres $(39,6 \%)$ não possuem filhos. Percebe-se, em um primeiro momento, que as mulheres têm fortes relações familiares, pois a maioria se encontra em um vínculo parental firmado, no qual há laços afetivos e emocionais fortes, com família constituída.

A maioria das respondentes se encontra com idade superior aos 36 anos, totalizando uma porcentagem de $95,6 \%$, e as mulheres com menos de 35 anos representam somente $4,4 \%$. Estes dados podem estar relacionados com a titulação e o tempo de docência, pois $83,7 \%$ das docentes são doutoras, e a maioria se encontra a mais de 22 anos na carreira. O mesmo pode ser verificado no Censo de Educação Superior do Ministério da Educação (MEC) realizada em 2013, que constata que nos últimos anos está havendo um aumento significativo e contínuo de doutores nas Universidades.

A maioria das docentes $(48,56 \%)$ conta com uma renda entre $R \$ 8.000$ a $R \$ 12.000$, resultado das classes ocupadas na carreira. A respeito das Universidades em que atuam, a amostra contemplou respondentes de todas as instituições Federais do Estado do Rio Grande do Sul, obtendo 132 respondentes da UFRGS, seguido da UNIPAMPA (98), UFSM (61), UFPel (43) e menos respondentes da FURG, com 7 docentes. Prevalecem as mulheres que trabalham na mesma Instituição de Ensino Superior em um tempo de até 6 anos (56,46\%), e grande parte ocupa a classe de adjunta (52,5\%) que é composta por professores doutores, confirmando o dado anterior no qual a maioria das docentes são doutoras.

Em relação à área do conhecimento, a maior concentração da amostra se encontra na área das Ciências Sociais Aplicadas (20,2\%), este dado pode se dar pela identificação com a área da pesquisa, Administração, que se situa nas Ciências Sociais Aplicadas. Curiosamente uma das áreas que obteve menos porcentagem foi a das Engenharias, que conforme Melo, Lastres e Marques (2004), mesmo com o avanço das mulheres engajadas em atividades científicas e mais bem qualificadas, ainda, por questões históricas, permanece pequena a presença feminina em áreas tradicionalmente ocupadas pelos homens, como engenharias e na pesquisa tecnológica aplicada. Ao serem indagadas se exercem atualmente algum cargo 
de gestão na Universidade, 55,9\% afirmam que não possuem, mas a porcentagem de quem exerce cargo de gestão se mostra considerável, atingindo $44,1 \%$.

Dessa forma, traçou-se o perfil das respondentes e passa-se agora, para a análise da percepção de sucesso das docentes.

\section{Percepção de Sucesso}

Esta escala pretendeu identificar a percepção de sucesso, através da interpretação pessoal de cada respondente sobre suas realizações em relação à carreira, ou seja, a sequência de atividades elaboradas e posições ocupadas até o momento em sua vida profissional. Primeiramente, a fim de verificar se a aplicação desta escala, neste estudo, é confiável analisaremos os valores de Alpha de Cronbach, para cada dimensão - Tabela 2.

Tabela 2- Escala EPSCR

\begin{tabular}{ccccc}
\hline Fatores & $\begin{array}{c}\text { Alpha de } \\
\text { Cronbach } \\
\text { (Validação) }\end{array}$ & Confiabilidade & $\begin{array}{c}\text { Alpha de } \\
\text { Cronbach } \\
\text { (Amostra) }\end{array}$ & Confiabilidade \\
\hline 1- Objetiva & 0,810 & Muito Bom & 0,811 & Muito Bom \\
2- Subjetiva & 0,800 & Muito Bom & 0,768 & Moderado \\
\hline
\end{tabular}

Fonte: elaborada pelos autores, com base nos dados da pesquisa.

Os índices de precisão apurados na validação da aplicação reduzida deste questionário obtiveram valores de Alpha igual a 0,810 para dimensão objetiva, e de 0,800 para a dimensão subjetiva. Observa-se na Tabela 2, que estes valores são bem próximos dos resultados aqui encontrados $(0,811$ e 0,768$)$, comprovando que os itens são satisfatórios e confiáveis. Sendo assim, é possível prosseguir com a análise com dos resultados da média, mediana e desvio-padrão, resultantes desta pesquisa.

Tabela 3 - Média, Mediana e Desvio Padrão.

\begin{tabular}{ccccc}
\hline Fator & Média & Mediana & Desvio Padrão & CV \\
\hline 1- Objetiva & 3,2758 & 3,4000 & 0,90531 & $27,64 \%$ \\
2- Subjetiva & 4,3978 & 4,6000 & 0,56687 & $12,89 \%$ \\
\hline
\end{tabular}

Fonte: elaborada pelos autores, com base nos dados da pesquisa.

Segundo Costa (2010), na tentativa de avaliar a EPSCR, pode-se considerar um fator como baixo quando sua média é menor ou igual a 2,0, médio quando a média se encontra entre 2,1 e 3,9, e alto quando alcançar valor igual ou superior a 4,0. Dessa forma, sugere-se que as respondentes consideram mais a interpretação subjetiva $(4,4)$ em relação à percepção de sucesso, do que a forma objetiva $(3,3)$ a qual se refere à opinião de terceiros. A dimensão objetiva envolve fatores objetivos e quantitativos, como salário ou posição hierárquica, observáveis por todos, são os resultados externos que terceiros avaliam, podendo ser 
assim chamado de "sucesso objetivo na carreira". Já a dimensão subjetiva, ocorre quando o indivíduo se autoavalia, considerando os sentimentos de realização e satisfação com a própria carreira.

Conforme os resultados das medianas, as mulheres se mostram indiferentes segundo o fator objetivo, sendo que metade delas está acima de 3,4 e metade abaixo. E são mais concordantes com o fator subjetivo, sendo que metade delas está acima de 4,6 e metade abaixo (SAMPIERI; COLLADO; LUCIO, 2006). E a partir dos resultados dos coeficientes de variação, percebe-se que as respondentes oscilam mais na percepção de sucesso de forma objetiva, do que subjetiva. Declarando não haver muitas oscilações quanto à percepção do sucesso subjetivo, fator positivo para a docente.

Nos achados de Costa e Dutra (2011), foram verificadas as principais fontes de percepção de sucesso da carreira percebida por docentes de instituições privadas. Dentre os fatores objetivo e subjetivo, os fatores subjetivos se relacionam mais com a percepção de sucesso, demonstram também, que pessoas que se sentem competentes no que faz e fazem o que gostam, sentem-se mais sucedidas do que aquelas que se sentem contentes com o seus salários e cargos. Estes resultados coincidem com os achados neste estudo, mesmo sendo com públicos distintos, das iniciativas privada e pública.

Ao finalizar a análise da escala separadamente, serão realizados os Testes $t$ de student, na intenção de obter resultados a partir de hipóteses formuladas através do embasamento teórico, podendo assim, verificar a diferença na percepção de sucesso na carreira das docentes segundo as variáveis: Filhos, Cargo de Gestão e Titulação Acadêmica.

\section{Percepção de Sucesso: Variável Filhos}

Como se pôde notar no perfil das respondentes (tabela 01 ), 60,4\% das docentes tem um ou mais filhos e 39,6\% não possuem filhos. Ter ou não filhos acarreta de forma direta nas atividades referentes ao trabalho e também na família (SHELTON, 2006) e por sua vez, pode influenciar na percepção de sucesso das mulheres. Assim, se determinou a hipótese: existe igualdade na percepção de sucesso das docentes que são mães em relação as que não são?

Para alcançar a resposta desta hipótese, usou-se do Teste $t$, sendo que os resultados podem ser verificados na Tabela 4.

Tabela 4: Teste t para a variável filhos.

\begin{tabular}{cccc}
\hline Variável & Média & $\mathbf{t}$ & Sig \\
\hline Com filhos & 3,8502 & & \\
Sem filhos & 3,8163 & 0,508 & 0,612 \\
\hline
\end{tabular}

Fonte: elaborada pelos autores, com base nos resultados.

A Tabela 4 revela que não há diferença na percepção de sucesso das docentes que tem filhos em relação as que não têm, tendo em vista o índice t $(0,508)$ e sig $>0,050$, o qual indica variância igual entre os grupos. Ou seja, a condição de ter ou não filhos não influencia na percepção de sucesso das docentes. 
Thimóteo et al. (2015) afirmam que tanto as mulheres solteiras e as casadas, com ou sem filhos, estão aumentando significativamente sua participação no mercado de trabalho e no serviço público, no qual se destacam demonstrando-se capazes de desempenhar tais funções, mesmo enfrentando desafios diários por serem mulheres. Assim, verifica-se que tanto mulheres com filho como aquelas sem, percebem sem diferenciação o seu sucesso na carreira, não havendo distinções a cerca da condição de ser ou não mãe. A seguir verifica-se a percepção de sucesso através da variável: cargo de gestão.

\section{Percepção de Sucesso: Variável Cargo de Gestão}

Como parte da estrutura das Universidades, existe a possibilidade de os docentes virem a assumir cargos de gestão de modo a auxiliar as atividades da IES nas funções gerenciais. Estes, por sua vez, agregam mais essa função, muitas vezes não deixando de lado a docência, podendo assim, desencadear situações nocivas, relacionadas à sobrecarga do cotidiano dos docentes. Dessa forma, levantou-se a hipótese: existe igualdade na percepção de sucesso das docentes que exercem cargo de gestão?

Para responder a esta hipótese a seguir tem-se a Tabela 5 que demonstra os resultados do Teste $t$ de Student.

Tabela 5: Teste t para a variável cargo de gestão.

\begin{tabular}{cccc}
\hline Variável & Média & $\mathbf{t}$ & Sig \\
\hline Com cargo de gestão & 4,0108 & & \\
Sem cargo de gestão & 3,6995 & 4,887 & 0,000 \\
\hline
\end{tabular}

Fonte: elaborada pelos autores, com base nos resultados da pesquisa.

Percebe-se que existe diferença, na percepção de sucesso das docentes que ocupam cargo de gestão, em relação as que não ocupam, tendo em vista o índice $t(4,887)$ e sig $<0,050$, indicando variância diferente entre os grupos. Atenta-se para o nível de significância de 0,000, isso permite afirmar, que a hipótese é aceita com um alto nível de segurança (HAIR et al., 2005). Ou seja, aquelas que ocupam cargo de gestão tem uma percepção maior de sucesso na carreira.

No estudo de Santos e Bronnemann (2012) são verificados os desafios enfrentados pelos gestores de uma IES, sendo apontado que um dos maiores desafios é ser avaliado de forma subjetiva sobre o seu desempenho no cargo de gestão. Então, este gestor acaba sofrendo com as constantes cobranças e expectativas depositadas, que assim como aponta a pesquisa, muitos deles estão no cargo, mas não são gestores natos. Diferentemente, este estudo revela que as docentes que ocupam cargo de gestão percebem um maior sucesso na carreira, deve-se isso talvez, ao prestígio de ocupar um cargo importante, pois, o progresso na carreira é avaliado pela ampliação das suas ocupações e a maior complexidade dos seus resultados (DUTRA, 2002).

Depreende-se que as mulheres docentes do Rio Grande do Sul atrelam a ocupação de um cargo de gestão a uma maior percepção de sucesso, sem considerar os impasses advindos dessa nova responsabilidade. A seguir, realizou-se a última análise envolvendo a variável: titulação acadêmica. 


\section{Percepção de Sucesso: Variável Titulação Acadêmica}

As docentes pesquisadas se enquadram, conforme Chanlat (1995), no tipo de carreira chamada profissional, que é aquela que prioriza o aumento do conhecimento específico. Obteve-se uma amostra com 298 doutoras, 56 mestres e 2 especialistas ${ }^{1}$. Dessa forma, realizou-se o Teste t para a hipótese: existe igualdade na percepção de sucesso das docentes que tem titulação de mestre ou de doutora? Na Tabela 6 apresentam-se os resultados do Teste.

Tabela 6: Teste t para a variável titulação acadêmica.

\begin{tabular}{cccc}
\hline Variável & Média & $\mathbf{t}$ & Sig \\
\hline Mestre & 3,6536 & & \\
Doutora & 3,8768 & $(-2,527)$ & 0,012 \\
\hline
\end{tabular}

Fonte: elaborado pelos autores, com base nos resultados.

O Teste possibilitou inferir que existe diferença na percepção de sucesso das docentes em relação ao título que possuem, devido o valor $\mathrm{t}(-2,572) \mathrm{sig}<0,050$, o qual indica variância diferente entre os grupos. Assim, é possível afirmar que docentes doutoras percebem mais o sucesso na carreira do que as mestras.

Mesmo que segundo Gomes e Alves (2015) afirmem que a titulação acadêmica é fator de destaque para ambas as titulações, a partir dos resultados aqui encontrados, percebe-se que as doutoras diferem das mestras em sua percepção de sucesso. Esta diferenciação pode vir a ocorrer devido a alguns benefícios que as doutoras usufruem, como por exemplo, a possibilidade de participar de alguns editais para concorrer a incentivos para obtenção bolsa de pesquisa, cita-se ainda a classe na carreira bem como a remuneração diferenciada em função da titulação.

Ao finalizar as análises pertinentes a este estudo, passa-se para as considerações finais.

\section{CONSIDERAÇÕES FINAIS}

No século XXI há uma maior valorização do conhecimento, porém, o ambiente profissional se tornou mais instável, uma vez que na medida em que aumenta o nível de conhecimento dos indivíduos, o mercado se torna mais competitivo. Assim, o profissional considera importante a interpretação subjetiva da sua percepção de sucesso perante a percepção objetiva, sendo mais significativa a sua realização pessoal no trabalho do que até mesmo o salário.

Este estudo se propôs identificar a percepção de sucesso na carreira das docentes do gênero feminino das Universidades Federais do Rio Grande do Sul. Este tema surgiu devido ao grau de complexidade que se instala na carreira do docente, agravado quando estas são mulheres, sendo que ainda são vistas como responsáveis pelas atividades do lar e da criação dos filhos.

\footnotetext{
${ }^{1}$ É possível verificar que duas docentes possuem titulação de especialista, porém, para a realização dessa testagem optou-se por analisar apenas as mestres e doutoras, uma vez que não foi possível rodar o teste ANOVA, tendo em vista a disparidade de respostas entre os grupos.
} 
Através da análise dos dados, percebe-se que a maioria das respondentes é casada, com idade superior aos 36 anos, sendo que mais da metade já são mães. São doutoras ou mestras na grande parte dos casos, ocupam a classe de adjunta na carreira, sendo que um pouco mais da metade das docentes não exercem cargos de gestão e possuem renda bruta pessoal entre $R \$ 8.000$ a $R \$ 12.000$. Denota-se que a amostra é bastante experiente contando com mulheres já bem capacitadas, assim, tem relevância o fato da maioria já ter filho. Demonstrando que a sua capacitação e seu desempenho no trabalho não foram impedimentos na hora de decidir sobre ter ou não filho, diferentemente do que propõem Shelton (2006), que acredita que essa decisão influencia diretamente as atividades do trabalho. Esse resultado se faz importante, ao apontar para uma relação positiva entre uma docente bem-sucedida e com filho ou filhos, desfazendo a visão desfavorável dessa condição da mulher.

O resultado da análise da escala EPSCR, revelou que as docentes percebem mais seu sucesso e o avaliam através da dimensão subjetiva que ocorre quando o indivíduo se autoavalia, considerando os sentimentos de realização e satisfação com a própria carreira. Já a dimensão objetiva, é menos relevante para a avaliação da docente. Fator favorável para a carreira da docente e também para a instituição para qual ela trabalha, sendo comprovado que estar em um ambiente agradável, que possibilita o bom relacionamento entre os colegas e ser reconhecido pelo que faz se torna mais importante do que apenas a sua remuneração. Assim a instituição pode criar maneiras alternativas para manter o seu docente satisfeito e disposto ao trabalho.

Os Testes $t$ de Student revelaram que tanto mulheres com filho como aquelas sem, não percebem diferença no sucesso de sua carreira, desse modo, não havendo distinções a cerca da condição de ser ou não mãe em relação à percepção de sucesso. Revelando que a condição de ser ou não mãe não interfere nas suas percepções, e que o filho ou filhos não são impedimentos para alcançar o sucesso na carreira. Já na hipótese da variável cargo de gestão, foi identificado que as docentes que ocupam cargo de gestão percebem mais sucesso na carreira, em relação as que não ocupam cargo de gestão. Esse resultado está associado à percepção subjetiva da carreira, pois um dos pontos importantes para essa avaliação é a valorização das suas atividades e o grau de complexidade das mesmas, assim a mulher percebe mais sucesso no momento em que está à frente de um cargo de maior responsabilidade organizacional. E por último, o teste da variável titulação acadêmica identificou que as doutoras percebem mais sucesso na carreira em relação às mestras. Esse resultado pode ser reflexo dos tipos de benefícios concedidos somente para doutoras, ou até mesmo, pelo motivo do teste anterior, no qual, as docentes doutoras percebem maior sucesso devido o nível de responsabilidades que o título acadêmico pode vir a trazer para sua vida, diferentemente da visão das mestras que percebem em menos grau o sucesso na carreira.

Dessa maneira, o estudo alcançou seus objetivos e consegue responder ao problema de pesquisa estabelecido inicialmente que era: Qual a percepção de sucesso na carreira das docentes do gênero feminino das Universidades Federais do Rio Grande do Sul? Assim, verificou-se que a percepção de sucesso das docentes do Rio Grande do Sul ocorre através da avaliação subjetiva, julgam suas carreiras através dos seus sentimentos de realização e satisfação com a própria carreira, ou seja, realizam uma autoavaliação, importando-se menos com a interpretação objetiva, realizada por terceiros, que consideram apenas circunstâncias mensuráveis. 
Este estudo traz uma abordagem que proporciona um maior entendimento sobre a forma com que as pessoas percebem e avaliam o seu sucesso, neste caso a percepção de docentes mulheres. Concedendo um olhar especial para as mulheres que enfrentam desafios diariamente em suas vidas profissionais $\mathrm{e}$ pessoais. Estes resultados podem vir a impactar a maneira como as organizações tratam a valorização dos seus funcionários, pois, nota-se que não é apenas as questões salariais que influenciam na realização e permanência do individuo no trabalho. E para o âmbito acadêmico, esta pesquisa é mais uma contribuição para um tema, já consolidado, porém, traz um viés pouco estudado, que une a docência com os desafios enfrentados pelas mulheres. Porém, este estudo limita-se a amostra estudada, não podendo realizar generalizações para toda a população.

E, por fim, sugere-se para estudos futuros, o uso de novas variáveis que podem vir a influenciar a percepção de sucesso na carreira tanto de docentes, como de outras profissões. Outra pesquisa relevante seria a adoção dessa mesma metodologia e temática, porém, explorar outro tipo de carreira profissional, na tentativa de realizar comparações.

\section{REFERÊNCIAS}

ALVARENGA, C. F. Relações de gênero e trabalho docente: jornadas e ritmos no cotidiano de professores. Dissertação de Mestrado. FE-USP. São Paulo, 2008.

ANDRADES, J. O.; BARBOSA, A. C. Q. Carreiras Femininas: Indo Além do Senso Comum - Um Estudo com Mulheres Profissionais Brasileiras. In: EnANPAD, 37, 2013, Rio de Janeiro/RJ. Anais Eletrônicos... Rio de Janeiro/RJ, EnANPAD, 2013.

ARTHUR, Michael B et al. Career Success in a Boundaryless Career World. Journal of organizational behavior. v. 26, p. 177-202, 2005.

BOTELHO, L. L. R.; MORAES, L. V. S.; CUNHA, C. J. C. A. Ascensão profissional feminina: um caminho bem mais tortuoso do que se imagina. Seminário Internacional Fazendo Gênero 8 - Corpo, Violência e Poder. Florianópolis/SC, 2008.

COLLIS, J.; HUSSEY, R. Pesquisa em Administração: um guia prático para alunos de graduação e pós-graduação. 2ed. Porto Alegre: Bookman, 2005.

COSTA, L. V. A Relação entre a Percepção de Sucesso na Carreira e o Comprometimento Organizacional: Um Estudo entre Professores de Universidades Privadas Selecionadas da Grande São Paulo. Tese de Doutorado. Universidade de São Paulo, São Paulo, 2010.

COSTA, L. V.; DUTRA, J. S. Avaliação da Carreira no Mundo Contemporâneo: Proposta de Um Modelo de Três Dimensões. ReCaPe - Revista de Carreiras e Pessoas. São Paulo, v. 01, n. 1, 2011.

COSTA, L. V.; CHIUZI, R. M.; DUTRA, J. S. Relações entre Percepção de Sucesso na Carreira e Comprometimento Organizacional: Um Estudo com Professores do Ensino Superior de Administração. Revista de Administração da UNIMEP. São Paulo, v. 11, n. 2, 2013.

COSTA, A. R.; VIEIRA, A. M. Percepção de Sucesso na Carreira, Bem-Estar no Trabalho e Desempenho: Um Estudo com Professores Universitários. Qualit@s Revista Eletrônica, v. 16, n. 2, 2014.

CHANLAT, J. F. Quais carreiras e para qual sociedade?. RAE - Revista de Administração de Empresas. São Paulo, v. 35 , n. 6, p. 67-75, 1995.

DUTRA, J.S. Gestão de pessoas: modelo, processos, tendências e perspectivas. São Paulo: Atlas, 2002.

GOMES, C. F. S.; ALVES, M. R. Uma Abordagem Comparativa Dos Planos De Carreiras E Cargos Do Magistério Superior Federal. ReCaPe-Revista de Carreiras e Pessoas. São Paulo. Vol 02, Mai/Jun/Jul/Ago. 2015.

GONÇALVES, J. A. Desenvolvimento profissional e carreira docente - Fases da carreira, currículo e supervisão. Sisífo Revista de Ciências da Educação. V. 08, p. 23-36, 2009.

HAIR, J. F.; et. al., Fundamentos de Métodos de Pesquisa em Administração - Tradução Lene Belon Ribeiro - Porto Alegre: Bookman, 2005.

HALL, D. T. Careers in and out of organizations. Thousand Oaks: Sage, 2002. 
JILOU, V. ; CECÍLIO, S.Condições de trabalho docente e sofrimento psíquico no ensino superior. Germinal: Marxismo e Educação em Debate, v. 7, p. 233, 2015.

JUDGE, T. A. et al. An Empirical Investigation of the Predictors of Executive Career Success. Personnel Psychology, v. 48, n.3, p. 485-519, 1995.

MEC. Censo da Educação Superior de $2013 . \quad$ Disponível em: http://portal.mec.gov.br/index.php?option=com_docman\&view=download\&alias=17199-cne-forum-educacao-superior2015-apresentacao-10-jose-soares\&Itemid=30192 Acesso em: 3 de Maio de 2016.

MELO, H. P. de; LASTRES, H. M. M. ; MARQUES, T. C. N. Gênero no sistema de ciência, tecnologia e inovação do Brasil. RevistaGênero, Niterói, v. 4, n.2, p. 75-96, 2004.

O'NEIL, D. A. Working in context: understanding the life-in-career experiences of women. Weatherhead School of Management. Western Reserve University. 2003.

ROWE, D. E. O.; BASTOS, A. V. B.; PINHO, A. P. M. Comprometimento e Entrincheiramento na Carreira: um Estudo de suas Influências no Esforço Instrucional do Docente do Ensino Superior. RAC, Curitiba, v. 15, n. 6, p. 973-992, 2011.

SAMPIERI, R. H.; COLLADO, C. F.; LUCIO, P. B. Metodologia de Pesquisa. 3ed. São Paulo: McGraw-Hill, 2006.

SANTOS, L.; BRONNEMANN, M. R. Desafios da Gestão em Instituições de Ensino Superior: Um Estudo de Caso a partir da Percepção de Diretores de Centro de uma IES Pública do Sul do Brasil. Revista GUAL, Florianópolis, v. 6, n. 1, p. 0121, jan. 2013.

SHELTON, L.M. Female Entrepreneurs, Work-Family Conflict and Venture Performance: New Insights into Work-Family Interface. Journal of Small Business Management. v. 44(2), p. 285- 297, Abr, 2006.

STURGES, J. All in a day's work? Career self-management and the management of the boundary between work and nonwork. Human Resource Management Journal, v. 18, n. 2, p. 118-134, 2008.

THIMÓTEO, P. M.; ZAMPIER, M. A.; STEFANO, S. R. Atuação feminina em cargos de liderança: a realidade de algumas empresas de uma cidade da mesorregião central do Paraná. Revista da Micro e Pequena Empresa, Campo Limpo Paulista, v.9, n.1, p. $53-75,2015$.

VEIGA, I. P. A. Projeto Político Pedagógico da Escola: Uma Construção Coletiva. Papirus Editora, 2005. 